My own observations were on 9 cases of ascites, the patient in each case being tapped in a sitting position. Three were tapped twice or more.

Constant Features.-During the drainage of the fluid, as a rule, a fall occurs in the arterial pressure that averages $32 \mathrm{~mm}$. The lowest pressure comes usually several minutes after the needle is withdrawn, but it may come at any time during the procedure. Once a fall of $62 \mathrm{~mm}$. took place in the first minute of drainage when 2,000 c.c. of fluid escaped in that length of time (Fig. 7). This fall was probably in the nature of a tem-

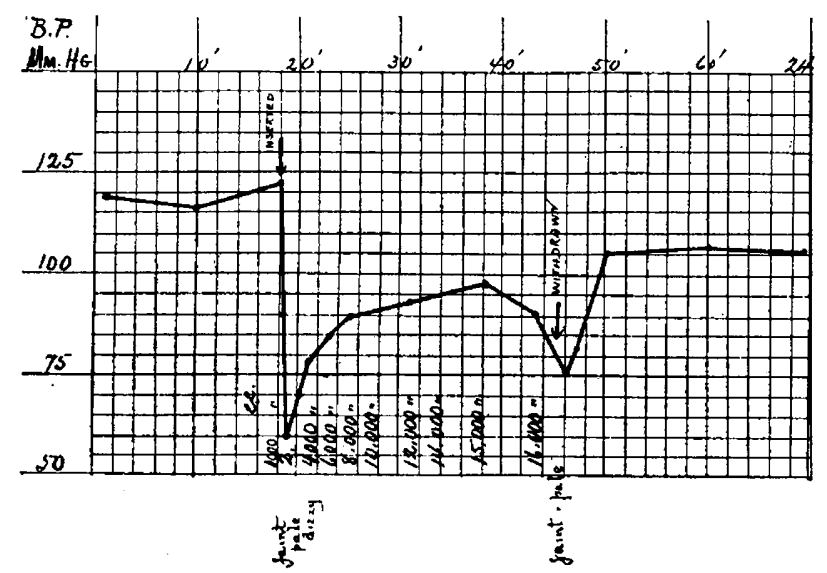

Fig. 7.-Case 7. Abdominal paracentesis; effect of very rapid withdrawal. improvement is most pronounced in those cases that undergo a marked fall in pressure during the operation.

Conclusion.-I realize that the number of observations here recorded is insufficient to warrant any final conclusions. It is desirable that records be made of the blood pressure curve in a large number of cases of thoracentesis in which simple siphonage without aspiration is employed. Finally, there is need of further experimentation with both mechanical and medicinal agents directed toward the prevention and relief of untoward circulatory symptoms occurring during the withdrawal of fluid.

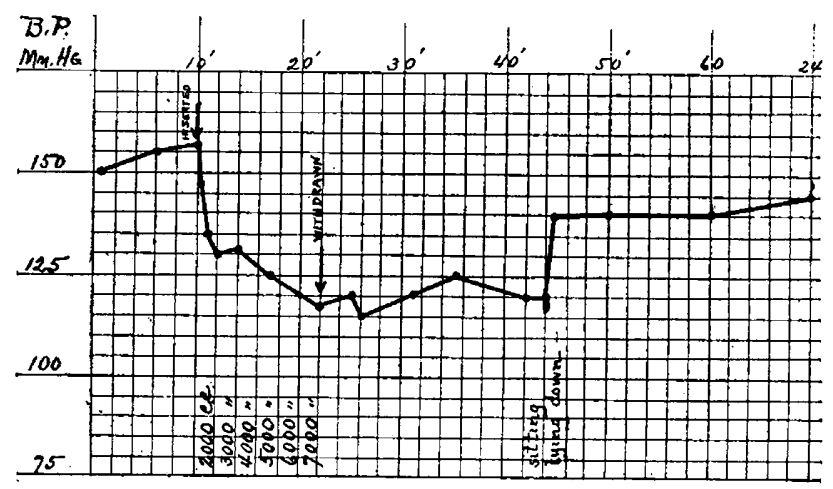

Fig. 8. Case 1. Abdominal paracentesis showing the effect of posture.

TABLE 2-PARACENTESIS ABDOMINIS

\begin{tabular}{|c|c|c|c|c|c|c|c|c|c|}
\hline \multirow[b]{2}{*}{ Case } & \multirow[b]{2}{*}{ Diagnosis } & \multirow{2}{*}{ 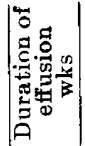 } & \multirow{2}{*}{ 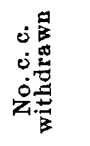 } & \multirow{2}{*}{ 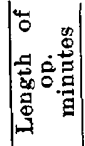 } & \multicolumn{4}{|c|}{ B. P. in $\mathrm{mm} . \mathbf{H g}$. } & \multirow[b]{2}{*}{ Remarks } \\
\hline & & & & & $\begin{array}{c}\text { Before } \\
\text { op. }\end{array}$ & $\begin{array}{l}\text { Mini- } \\
\text { mum }\end{array}$ & $\underset{\text { Tatal }}{\text { Total }}$ & $\begin{array}{c}\text { One hr. } \\
\text { after }\end{array}$ & \\
\hline $\begin{array}{l}1 \\
1 \\
\frac{1}{2}\end{array}$ & $\begin{array}{l}\text { Ascites, nephritis, cirrhosis of liver. . . } \\
\text { Ascites, nephritis, cirrhosis of liver } \ldots \ldots \\
\text { Ascites, cirrhosis of liver } \ldots \ldots\end{array}$ & $\begin{array}{l}3 \\
5 \\
4\end{array}$ & $\begin{array}{l}7,000 \\
6,700 \\
3,000\end{array}$ & $\begin{array}{l}16 \\
13 \\
16\end{array}$ & $\begin{array}{l}150 \\
144 \\
146\end{array}$ & $\begin{array}{l}115 \\
115 \\
106\end{array}$ & $\begin{array}{l}35 \\
29 \\
40\end{array}$ & $\begin{array}{l}\mathbf{1 2 5} \\
132 \\
120\end{array}$ & \multirow{6}{*}{ 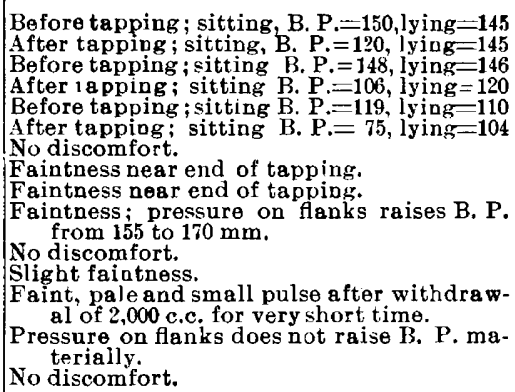 } \\
\hline 3 & Ascites, cirrhosis of liver . . . . . . & 3 & 3,000 & 14 & 118 & 60 & 58 & 104 & \\
\hline $\begin{array}{l}4 \\
5 \\
5 \\
5\end{array}$ & $\begin{array}{l}\text { Ascites, nephritis, dilated heart. } \ldots \\
\text { Ascites, nephritis. } \ldots \ldots \ldots \\
\text { Ascites, nephritis } \ldots \ldots \ldots \\
\text { Ascites, nephritis } \ldots \ldots \ldots\end{array}$ & $\begin{array}{l}2 \\
4 \\
7 \\
8\end{array}$ & $\begin{array}{l}1,000 \\
6,000 \\
7,500 \\
6,500\end{array}$ & $\begin{array}{l}12 \\
14 \\
22 \\
15\end{array}$ & $\begin{array}{l}160 \\
145 \\
172 \\
176\end{array}$ & $\begin{array}{l}144 \\
120 \\
148 \\
145\end{array}$ & $\begin{array}{l}16 \\
25 \\
24 \\
31\end{array}$ & $\begin{array}{l}158 \\
130 \\
155 \\
165\end{array}$ & \\
\hline $\begin{array}{l}6 \\
7 \\
7\end{array}$ & $\begin{array}{l}\text { Ascites, myocarditis nephritis } \ldots \ldots \ldots \\
\text { Ascites, cirrhosis of liver. } \ldots \ldots \ldots \ldots \\
\text { Ascites, cirrhosis of liver. . }\end{array}$ & $\begin{array}{l}3 \\
4 \\
5\end{array}$ & $\begin{array}{r}6,000 \\
21.500 \\
16,000\end{array}$ & $\begin{array}{l}13 \\
33 \\
27\end{array}$ & $\begin{array}{l}160 \\
125 \\
116\end{array}$ & $\begin{array}{r}140 \\
86 \\
60\end{array}$ & $\begin{array}{l}20 \\
39 \\
56\end{array}$ & $\begin{array}{l}155 \\
104 \\
108\end{array}$ & \\
\hline 8 & Ascites, cirrhosis of liver . . . . & 2 & 3,500 & 24 & 95 & 80 & 15 & 90 & \\
\hline 9 & Ascites cirrhosis of liver $\ldots \ldots \ldots \ldots$ & 4 & 8,000 & 22 & 100 & 95 & 8 & 100 & \\
\hline
\end{tabular}

porary collapse due to a sudden relaxation of the splanchnic vessels. In other instances the fall in pressure was very slight. The final pressure taken an hour or more after paracentesis on an average is $12 \mathrm{~mm}$. lower than the initial pressure. This decrease corresponds closely to the average fall of 10 to $14 \mathrm{~mm}$. in the intraabdominal pressure after tapping that was noted by Quirin.

Special Influences.-The rate of withdrawal seems more important than the amount of fluid removed in its effect on the immediate fall in arterial pressure. The final pressure, however, is more affected by the amount of fluid. External pressure on the abdominal wall at the end of drainage often raises the pressure 5 to 20 $\mathrm{mm}$. This acts in the same way as Crile's pneumatic suit in shock in supporting the splanchnic vessels and relieving abdominal engorgements. Posture is important. Normally the pressure is higher in the sitting than in the recumbent position. At the end of paracentesis, however, lying down often increases the pressure 6 to $20 \mathrm{~mm}$. (Cases 1, 2 and 3 , Table 2). The

\section{ACUTE INFECTIONS OF THE THORACIC CAVITY.*}

J. H. MUSSER, M.D. PHILADELPHIA.

This paper is limited to a consideration of empyema in its earliest stage, when loculated, first, between the lung and the chest wall; second, between the lobes, interlobar; third, between the diaphragm and the lung. It should be our aim to determine the presence of small collections of pus in the pleural cavity. It is no credit to the profession at the present time to send to the surgeon a patient with the chest half filled with pus or even with half a pint or a pint of such accumulation. Members of the profession have not taken to heart the lessons of Murphy, ${ }^{1}$ Willard ${ }^{2}$ and Eisendrath ${ }^{2}$ and the

* Read in the foint session of the Sections on Practice of Medicine and on Pathology and Physlology of the American Medical Association, at the Fifty-seventh Annual Session, June, 1906.

1. "Sirgery of the Lung," THE JodnNaL, A. M. A., July 23, 1898 , p. 151 .

2. The Jodrnal A. M. A., Sept. 20, 1902, p. 665. 
excellent essays and reports of Withington, Sears, Jackson, Munro and others. ${ }^{3}$

The force of the necessity of recognizing eariy small collections of pus can be appreciated only when we recall the disastrous results that follow accumulations of large amounts, either from general systemic infection or from the local changes in the lungs, the pleural cavity, or the chest wall. One can scarcely conceive of the crippling effects of such accumulations without unfortunate practical experience. I am one of those who believe the compression of the lung, even by a sterile fluid, is not good for the patient or for the lung.

To recognize the local small collections of pus a careful study of the clinical course of the disease, which includes a careful history of the case, a consideration of the general and local symptoms, a study of the physical signs, the use of the $x$-ray, and, if necessary, the employment of exploratory operation, is essential.

The frequency of occurrence of empyema can not be accurately estimated. Reliable statistics exist as to the frequency after pneumonia. (Table 1.)

table 1.-Frequency of Empyema after Pneumonia.

\begin{tabular}{c|c|c|c}
\hline \hline & Empyema. & Abscess of Lung & $\begin{array}{c}\text { Gangrene of } \\
\text { Lung. }\end{array}$ \\
\hline $\begin{array}{c}\text { Clinical Reports: } \\
\text { University Hosp. }\end{array}$ & 0 in 45 & 0 in 45 & 0 in 45 \\
$\begin{array}{c}\text { Presbyterian Hosp. } \\
\text { Collected from } \\
\text { literature. }\end{array}$ & 9 in $489,1.8 \%$ & $21 \mathrm{n} 489,0.4 \%$ & 0 in $12,892.2 .1 \%$ \\
$\begin{array}{c}\text { Autopsy Reports: } \\
\text { Collected from } \\
\text { literature. }\end{array}$ & 50 in $973,5.1 \%$ & 28 in $12,030,0.63 \%$ & 136 in 27,761,0.49\% \\
\hline \hline
\end{tabular}

There seems to be some well-founded evidence that many of the cases of so-called unresolved pneumonia are either cases of empyema, small and loculated, or cases of abscess of the lung. Jackson's recent paper points out the very great infrequency of unresolved pneumonia, and $I$ am bound to admit that I have never seen a case to which I could apply this term.

\section{CLINICAL COURSE.}

The clinical course can be better appreciated when we recognize that empyema is local and secondary at first, and, even more broadly still, that infectious pleuritis, as peritonitis, is never primary. There is some focus of infection in relation to the pleura which is a starting point of the inflammation.

The history of the disease is of importance in the recognition of the infection. The usual antecedents that precede an empyema are: (a) Serous pleurisy; (b) pneumonia; (c) typhoid (from ribs); (d) scarlet fever; (e) local conditions (fractured rib, gullet, etc.). The history of the course of any one of these conditions in a patient in whom there is suspected infection within the thorax aids in the diagnosis.

\section{SYMPTOMS.}

The general symptoms are those of an infection occurring in the course of or after one of the primary antecedents named above. They may be of gradual onset, characterized by fever, sweats, the usual phenomena of infection with the occurrence of leucocytosis. In young individuals the symptoms are usually very frank. In older persons, and those suffering from primary disease elsewhere, as of the kidneys or the liver, the symptoms may be ill-defined and in large part in abeyance.

I was much interested in two cases recently under my care in old individuals in whom the primary infection

3. Published during the Iast two or three years in the Boston Medical and Surgical Journal. was not characterized by very marked symptoms. Both were the subject of pneumonia. In one patient, aged 78, the general symptoms were very mild. Notwithstanding well-marked signs of consolidation, the temperature never rose above 100.5 and $101 \mathrm{~F}$. After the subsidence of the pneumonic symptoms with the gradual development of the secondary infection of the pleura, the febrile symptoms were more pronounced and typically hectic. The toxemia of the primary infection no doubt modified the clinical course in the beginning. As the toxemia disappeared the septic symptoms of the secondary infection became more pronounced so that an evening temperature of 102.5 or $103 \mathrm{~F}$. was the rule.

In the second instance the general symptoms of the first period were very irregular, while the fever was not suggestive of a pneumococcus infection. In the second period, with the development of the empyema, the characteristic fever of this infection occurred. Reliance must be placed in these instances of the gradual onset of the general symptoms on the leucocytosis. This is undoubtedly a very important symptom. It is likewise notably present in the period of secondary infection, although it may be absent with the primary disease. In the empyema following typhoid fever I have usually found a leucocytosis, although not to the same degree as it occurs after pneumococcus infection. It may be said in passing that usually such infection, in my experience, was developed from a periostitis of one of the ribs.

In not a few instances the onset of the symptoms is sudden, especially if the infection is streptococcic. This is particularly true in cases following scarlet fever and in those which develop in the course of a serofibrinous pleurisy. A chill marks the onset, high temperature follows and persists, with the usual septic phenomena.

I must earnestly beg internists not to mask constitutional symptoms by drugs. Much has been written of the dangers of opium in abdominal diseases because it masks the signs. Just so antipyretics, even of the mildest form, mask the constitutional signs of an infection apart from the great danger to the heart and nervous system. I have seen large doses of quinin keep down the temperature to such a point that it was thought there was no abscess, but only delayed resolution.

Local Symptoms.-I shall not dwell on any local symptoms except the occurrence of pain and tenderness.

Pain: When pain occurs it is usually an indication of the site of the focus of infection, barring those instances in which it is transferred. Thus, when the infection begins in a diseased rib or following a fracture, the pain may not be complained of at the seat of the lesion, but on the anterior portion of the chest at the exit of the branches of the intercostal nerve. As in all instances of pain, our studies must be on the lines laid down by Hilton, Head and MacKenzie. It is well known that the pain of diaphragmatic pleurisy may be anterior while the disease is progressing. I have not been able to corroborate the statement that such pain may be felt in the neck at the point of origin of the phrenic nerve. It is very certain, however, that in the scapular region there may be pain because of diaphragmatic infection for the same reason that in certain forms of liver disease there is scapular pain.

Tenderness: Localized tenderness is a far more important symptom than pain. The toxic state of the patient may be such that he would make no complaint of ordinary pain. If, however, the chest is carefully examined with firm and deep pressure, following, especially 
in the interspaces, the septa which divide the lobes of the lung, one will almost surely detect a point of tenderness suggestive of the localization of the purulent collection. Deep pressure may be necessary to bring it out. Such exploration along the margin of the diaphragm or the upper borders of the liver may help also to localize the infection."

In the case of a medical friend recently under my care, with others, the patient himself could circumscribe with his own finger the point of tenderness around the purulent collection. Dr. Fussell will recall the case which we aspirated without success at a certain point because the physical signs indicated the localization of the abscess in this region. When the needle was inserted in the upper axillary region over the septa and at a point where tenderness was elicited, pus was secured at once. I am so impressed with the importance of this sign that $I$ would almost prefer to say nothing further in the paper in order that its value could be more strongly emphasized.

\section{PHYSICAL SIGNS.}

When the collections of pus are small and between the lobes, it can readily be surmised that the physical signs will be indefinite and perhaps, even, may be almost wanting. In a case with the history previously mentioned in which symptoms of infection arose, recognition must be taken of the slightest departure from the normal and stress laid on it. Of such signs the occurrence of impairment of movement or expansion will perhaps be one of the first detected. Such impairment may be limited to an apex when pus is developed between the lobes or to the base when the diaphragm is the site of infection. If the latter, the excursion to the diaphragm as indicated by the method of Litten will afford a valuable clue as to the possibility of pus in that neighborhood. Early in the disease the fremitus may or may not be modified. If careful comparisons are made, interspace by interspace, in the larger majority of instances it will be absent or deficient. One must remember, however, that consolidations in front of the abscess may conduct vibrations and may be somewhat confusing.

Percussion Note: The percussion note is of very great value and three points particularly are worthy of consideration:

1. The area of modified resonance or dulness is in the beginning fixed. The fluid is not in sufficient quantity to change position. Modification of the note on inspiration and expiration is of great value in determining the localization of the abscess. Change in the character of the note when the patient changes from the upright to the recumbent posture, when this is practical, is of as much importance as we know it to be in the determination of the presence of cavities.

2. The position of the area of dulness or modified resonance. When the abscess is between the lobes the area of percussion dulness will have direct relation to the septa. When the abscess is near the surface between the lobes the dulness may be at any point along the septa. When it is deep the area of dulness will be below the lines dividing the lungs. Thus, an abscess between

4. Subsequent to the reading of the paper I wish to add a note to emphasize this very Important symptom. In the discussion, one of the speakers stated that pain was not of common occurrence. With thts I am in accord. Tenderness, however, is very common and is a very important indication of the position of the abscess. On the day of my return from this session I saw a case in consultation with Dr. Stahl, and we were able to localize the accurnilation positively by the occurrence of this sign. An operation by Martin proved the truthfulness of the observation. the upper and lower lobe of the left lung deeply situated will give signs posteriorly an inch or two below the margins of the lobes indicated, directly beneath the chest wall. The marginal line is along the fourth rib behind and the fifth in the axilla, and in front. The dulness would be below this point. If the abscess is on the dome of the diaphragm the first indications of impaired resonance will be not at the extreme bases, but from three to four inches above the base on the left side, and from one to two inches above on the right side. In general, it may be said that in localizing small abscesses on $\epsilon$ must confine oneself to an exploration of the mid-regions of the chest or of the diaphragm. Following the lines of the septa I have localized abscesses posteriorly behind the scapula (case of Dr. Nock), in the upper axillary region (case with Cheston), above the heart (case with Martin), in the second and third interspaces on the right side anteriorly (case with Allig), and in the fifth interspace in the same region (case with Deaver).

3. Skodiac resonance is a sign of the very greatest importance. Its occurrence anteriorly, latterly, and especially when in relation to the margins between the lobes, furnishes a valuable clue to the localization of a purulent collection. In not a few instances it may be elicited in very decided degree, when at the same time fremitus and the breath sounds over the hyper-resonant area may be entirely absent. I have never seen this combination of phenomena occur except in cases of localized purulent collections either between the lobes or at an opposite point from the resonant area. My attention has been directed to it a number of times, and in no instance was consolidation found.

The shape of the area of dulness is not of very great significance. I think I am warranted in saying that in those collections which begin over the diaphragm and come out underneath the lung we may find it gradually rising in a $\mathrm{V}$ shape with the base downward in the postaxillary or scapular line. This, of course, has in part physical reasons for its development. When large effusions are present, it is well known that the highest point of the effusion, as demonstrated by Gannett, is on this line.

Auscultation.-Small collections give very little change of auscultation phenomena, save, perhaps, the diminution in breath sounds corresponding to the diminution in expansion. Again, with general symptoms of infection, and a previous history of thoracic difficulty, if we auscultate along the margin of the lobes, the presence of pleural frictions will in all probability be detected. Such frictions must be noted, as they may be the earliest indication of the localization of the abscess. I have demonstrated this to my satisfaction, and have made it, with tenderness on pressure, a guide point for further exploration.

Nothing, of course, is to be said of enlargement of the affected side, of the dislocation of the organs, of interference, of movement, or the presence of flatness or of movable dulness, as these are the signs of large collections which are not considered in this paper. It is small collections that we want to recognize.

\section{USE OF X-RAYS.}

Studies have been made by Talley and Newcomet with the $x$-ray and the fluoroscope in my wards. Their conclusions are that the value of the Roentgen ray in detecting these conditions in the chest is variable. It is the comrnon experience of a thickened pleura in this a previous consolidation without much thickening of the 
pleura, and the shadow is less uniformly dense than that of fluid in the pleura, so that under such circumstances a loculated empyema or a full abscess cavity is apt to stand out by its dense shadow in contrast to the less homogenous shadow of the resolving pneumonic consolidation. In similar circumstances, an empty cavity is even more evident, surrounded as it usually is by its wall. One case showed that an area of bronchiectasis with bronchial tubes filled with secretion, simulated an abscess. The mistake was all the more natural, as there existed above a well-defined cavity of an abscess that had discharged.

\section{EXPLORATORY PUNCTURE.}

I am not advocating exploratory puncture, notwithstanding the fact that in the body of the paper cases are referred to, in which I have resorted to exploratory puncture. No doubt there are instances in which it may be justifiable to do it as a means to localization. I believe the day is not far distant when we will be just as much in dread of introducing the needle into the thorax as we are of introducing it into the abdominal cavity. With the surgeon present and ready to operate at once, I am willing to admit that it may be employed. I feel, however, that it must not be relied on as a means of diagnosis. The failure to localize pus by means of such puncture occurs so often as to mislead and to allow dangerous dilly-dallying. Such failure arises in part from the small size of the abscess, although I believe that with attention to details in examination, at the present day, we can suspect its location with greater accuracy than formerly.

Another cause of failure lies in the instrument itself. I have repeatedly seen the day for further exploration put off because no pus was obtained, and this arose because of the imperfection in the instrument. There is no doubt that more can be accomplished with a largesized instrument than with the small ones usually advised, and that the trochar and canula are probably preferable to the aspirator.

It may be eaid in passing that this needling to determine the localization of pus is just about as negatively dangerous when abscesses are present in other locations than the thorax. The danger arises for the reasons above mentioned. Within the year a much-beloved and most able member of the profession lost his life from a subpectoral abscess, the presence of which was overlooked, because on needling in the region no pus could be detected. Incision by Deaver later showed the presence of a large collection, but unfortunately general sepsis had gone too far to save the life of the patient. Recently I saw a case of abscess about the hip joint, missed by needling, which led to grave destruction of the ischium before the knife showed its precise location. I can not see why surgeons will not undertake a little dissection and direct exploration rather than trust to the uncertainty of needling in cases of undoubted infection, the localization of which in a general way is usually made manifest by symptoms such as pain and tenderness.

\section{EXPIORATORY OPERATION.}

Realizing the danger from infection of the lung or of the healthy pleura by exploratory puncture, or the failure in not localizing pus in such puncture, we feel bound, in a large majority of cases, to advise direct exploratory procedure. Of course, it must be borne in mind that no one but an educated and experienced surgeon should be allowed to resort to such operation. I sympathize very much with the internist who has not at his right hand a competent surgeon to aid him in the management of cases of this character. It is far better, of conrse, to play a waiting game, and even to resort to exploratory puncture if one can not command the services of a trained surgeon. I realize that in urging exploratory operation the surgeon may have many problems to work out. I believe that the time is rapidly coming, however, when the technic of thoracic surgery will be as well worked out as that of abdominal surgery. If we do not have courage to go at it now and attempt to solve the problems they never will be solved.

So far as I can see, the mooted points are as to the choice of the anesthetic and the mode of procedure. It is for the surgeon to determine whether the operation should be done in two steps or not. From cases which I have had with Willard, notably the case of abscess of the liver, opened directly through the pleura, I take it that stitching the pleura together and making a definite field of operation is without danger. I have no doubt that the matter of packing, as in abdominal surgery, will be further developed with advantage to the operator. I am all the more urgent in insisting on exploratory operation, because in a considerable experience, in association with a number of operators, I have never seen any harm come from opening the thorax. It has not been my bad fortune to see a dangerous pneumothorax arise. Keen tells me that it has never occurred in his large and bold experience. The O'Dwyer-Fell apparatus for artificial respiration can generally overcome any untoward symptoms.

TABLD 2.

DEITH OF THE BLOOD VESSELS AT ROOT OF TAE LONGS FROM THE SKIY SORFACE OF CHEST, DFTERMINED BY MUASUERMENT ON TRANSVERSE SECTION OF FROZEN BODY OF AN AVERAGR ADULT MALE, BY DR. GEORGE MORRIS PIERSOL."

Measurements at level of junction of third costal cartilage with sternum (6th dorsal vertebræ):

RJght Lung.

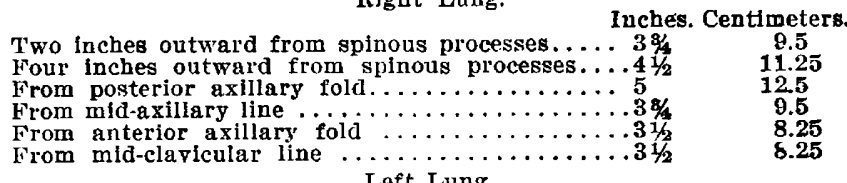

From anterior axillary fold $\ldots \ldots \ldots \ldots \ldots \ldots .31$ Left Lung.

Two inches outward from spinous processes......3\% Four inches outward from spinous processes.....4 From posterior axillary fold $\ldots \ldots \ldots \ldots \ldots \ldots 5$

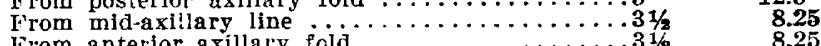
From anterior axillary fold ............... sternum (seventh dorsal vertebræ). Right Lung.

Two inches outward from spinous processes.....3 $1 / 2$

Four inches outward from spinous processes $\ldots \ldots \ldots 41 / 4$
From posterior axillary fold $\ldots \ldots \ldots \ldots \ldots \ldots \ldots \% 4$ From mid-axilary line $\ldots \ldots \ldots \ldots \ldots \ldots \ldots 4,10$ From anterior axillary fold $\ldots \ldots \ldots \ldots \ldots \ldots \ldots \ldots \ldots \ldots \ldots \ldots \ldots \ldots$
From mid-clavicular line $\ldots \ldots \ldots \ldots \ldots$ Left Lung.

Two inches outward from spinous processes..... . 3\% Four inches outward from spinous processes. . . . 4

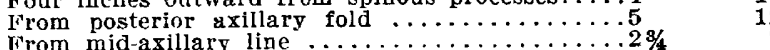
From anterior axilary line and midclavicular ine, the heart prevents introducing needle.

Apart from the point that there is no harm, all arguments that may be employed for exploratory operation in diseases of the abdomen can be used to support the procedure in diseases of the thorax. The precision in diagnosis that follows, the prevention of sepsis and of the secondary effects thereof on the heart and kidneys, the prevention of lung destruction or such compression of the lung as to incapacitate it, the prevention of chestwall destruction and deformities are accomplished by

5. My best thanks are due Dr. Piersol for the measurements made on several bodies with care and skill. 
the early removal of the purulent accumulations. I might add that such exploratory operation admits of complete examination of the entire thoracic cavity.

Table 2, which shows the distance from the chest wall at various points of the vessels, indicates the ease with which all points may be reached by the finger or the trochar.

\section{DIAGNOSIS.}

I will not take up the time of the Section with a consideration of the differential diagnosis of the various forms of intrathoracic infection. We must realize that such infection may be due to tuberculosis on the one hand or to multiple abscess of the lung on the other, neither of which can readily be the subject of surgical management, and must, therefore, be differentiated from empyema, pulmonary abscess and gangrene. In a future communication I hope to take up in detail the diagnosis of these infections. I would point out here that pulmonary tuberculosis has a clinical course that differs from the one under consideration; that it is not attended by a leucocytosis; that the pulse rate is out of proportion to the local signs; that the respiration rate is greater than the physical signs; that the signs may be present in one or more localities, and that the enlargement of the glands above the clavicle and in the neck is of more common occurrence than we are led to believe. Of course, the finding of tubercle bacilli or securing of the tuberculin reaction renders the consideration of all other phenomena unnecessary. I must admit that the difficulties are very great. I feel that in these more acute tuberculous infections in which there are no sputa, we will be more likely to find bilateral lesions than in the infections of the pleura due to pus-producing microoganisms. The $x$-ray and fluoroscope will enable us to define the multiplicity of the lesions. Multiple abscess of the lung is also difficult of recognition. It usually follows a bronchopneumonia, either of streptococcic origin or due to influenza, and generally the sputa will suggest the nature of the lesion. The physical signs are those of small areas of consolidation and then of cavity formation rather than of pleural lesions. When cavity formation occurs the pus has the usual characteristics.

Subpectoral Abscess. - I have seen three cases of subpectoral abscess which had been considered of intrathoracic origin. The general phenomena are out of proportion to the puImonary symptoms and even to the physical signs. Because of the location of the abscess, norinal respiratory signs may be so modified as to suggest intrathoracic disease. The history of the case and the examination, as well as the results of exploratory operation, will be sufficient to localize the lesion.

TREATMENT.

What has been said anticipates my statement that empyema at this or any other period of its development is a surgical disease. $\breve{M}$ plea to the internist, therefore, is to attempt to make a diagnosis as early as possible, and in cases of doubt to have the advice of the surgeon at once. It is more than criminal to delay and almost as criminal to explore. Let us be willing to give up this last semblance of our fading surgical power, the exploratory needle, and early beseech the surgeon to open the chest for direct exploration and immediate treatment. My plea must extend also to the surgeon to the effect that he more closely study procedures for the relief of thoracic infections and not enter in a half-hearted way on this field that belongs to him. I speak very feelingly, for I have to lay up against the surgeon not a few instances of failure to relieve pulmonary abscesses when they were present, or to secure pus when purulent accumulations were undoubtedly present. Iret him not delay until pus is so obviously present that the merest tyro with a hypodermic needle can reach it or can demonstrate it by the physical signs of pleural effusion. It is too late then, as forcibly comes to me when I recall the case of one patient who was allowed to go on, and although a late operation relieved him of pus, death took place because he was worn out, a termination which could have been averted if an operation had been done two weeks before.

I can not let the occasion pass without expressing my conviction that not only will we consider purulent accumulations of the chest as a surgical disease, but also conditions of serous membranes of inflammatory origin. I feel with Delafield that the sooner we get rid of this accumulation the better, and that surgical measures alone can bring it about.

\section{THE TREATMENT OF PLEURISY WITH EFEUSION.* \\ F. FORCHHEIMER, M.D. CINCINNATI.}

A number of explanations have been offered to show how a serous effusion is removed by Nature. It seems important to take these into consideration here, not because it is always best to imitate Nature in removing pathologic conditions, but in order that we may have a rational basis for our therapeutic methods. The oldest explanation is that of absorption of the fluid. It is evident that absorption may take place either by blood vessels or by lymphatics, but as a matter of fact absorption by blood vessels was usually referred to when the term absorption was used. Absorption by the blood vessels takes place through the veins; increased intrapleural pressure increases it, but when this pressure is too great the veins themselves become compressed and absorption ceases. S. West ${ }^{1}$ claims that this method of absorption plays a very small part in the removal of fluid from the pleural cavity. He insists that absorption takes place through the lymphatics. He states that the pleural cavity is a lymph cavity, its lining is that of endothelial cells, between which there are somata which form the beginnings of lymph capillaries. These lymph vessels have valves directed away from the pleural cavity and they finally empty themselves into the thoracic duct. The mechanism for the removal of a serous effusion is that of a "Iymphatic pump," which acts during respiration in increasing the flow of lymph. When there is a great effusion lymphatic absorption is entirely suspended, because expiration can not take place on the side affected and the pump is stopped.

It is more likely, however, that the compression of the lung by the pleuritic effusion is the predominating factor in the prevention of absorption, as by it the stomata and the lymph vessels, as well as the veins, are compressed which, in the latter, finally terminates in a paretic condition. This, moreover, would also explain the lack of absorption in a small effusion which, although to a less extent, produces the same effect on the lung surrounded by it, as a very large one. That this intrapleural pressure

* Read in the joint session of the Sections on Practice of Medicine and on Pathology and Physiology of the American Medical Association, at the Fifty-seventh Annual Session, June, 1906.

1. West, S. :"The Treatment of Pleuritic Effusion by Paracentesis," etc., Lancet, March 25, 1905. 